\title{
Atrioventricular Conduction in Atrial Fibrillation: Pathophysiology and Clinical Implications
}

\author{
Attila Roka \\ Hospital of St. Raphael, \\ USA
}

\section{Introduction}

The atrioventricular (AV) node is the only conduction pathway between the atria and ventricles, it is located at the base of the right atrium. The conduction through the atrioventricular node is slow to allow the atria to pump blood into the ventricles before they contract. It also acts as a backup pacemaker, in case the sinoatrial node fails and limits the number of action potentials conducted to the ventricles during atrial fibrillation (AF). Despite this filtering function, adequate ventricular rate control in atrial fibrillation often requires utilization of pharmacological and/or non-pharmacological treatment modalities.

\section{Functional anatomy of the atrioventricular junction}

The AV node is part of the cardiac pacemaker and conduction system. It develops from the embryonic myocardium that maintains essential features of its primitive phenotype, while the adjacent myocardium differentiates into working myocardium (Bakker et al., 2010). The AV node is a heterogenous structure, histologically consists of 3 layers: superficial/subendocardial, intermediate/midpart and deep innermost. A central fibrous body surrounds the distal structures (compact node and penetrating bundle), while the proximal part merges with the atrial myocardium via the inferior nodal extension and the transitional zone (Figure 1).

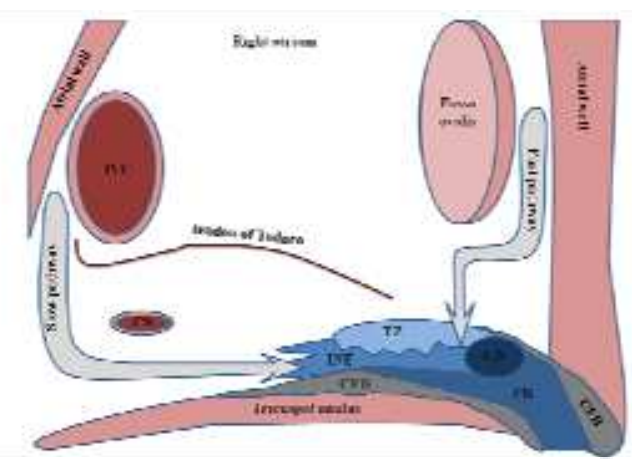

Fig. 1. Schematic anatomy of the AV node. View from the right atrium. IVC: inferior vena cava. CS: ostium of the coronary sinus. CFB: central fibrous body. INE: inferior nodal extension. TZ: transitional zone. PB: penetrating bundle. $\mathrm{CN}$ : compact node. 
Based on the morphology of the recorded action potentials, there are 3 distinct regions: atrionodal, compact nodal and nodo-His. At least 6 different cell types have been described so far based on action potential morphology, excitability and refractory period. The correlation between histologic, microstructural and electrophysiological properties is still not fully elucidated despite recent advances in this field using voltage-sensitive fluorescent dyes. The slow and fast pathways of AV nodal activation involve extranodal areas in the right atrium, in posteroinferior (crista terminalis) and anterosuperior (interatrial septum) locations, respectively. The AV node receives both sympathetic and parasympathetic innervation (Meijler \& Janse, 1988; Kurian et al., 2010).

\section{Ion channels, currents and their modulation in the atrioventricular node}

The electrical activity is determined by the expression of ion channels in the myocytes making up the conduction system. The ion channel expression in the AV node is specialized, similar to the sinoatrial node. There is very little expression of $\mathrm{K}_{\mathrm{ir}} 2$ channels, responsible for the $I_{K, 1} \mathrm{~K}^{+}$current, the main current to keep working cardiomyocytes at a negative resting potential. Other $K_{\mathrm{ir}}$ channel subunits $\left(\mathrm{K}_{\mathrm{ir} 3} 3.1, \mathrm{~K}_{\mathrm{ir}} 3.4, \mathrm{~K}_{\mathrm{ir}} 6.2\right.$ and SUR2) are also poorly expressed in the nodal tissues. The hyperpolarization-activated cyclic nucleotide-gated $\mathrm{Na}^{+}$ channels, responsible for the pacemaker current $I_{f}$, are highly expressed in the sinoatrial and atrioventricular node. Conduction through the AV node is slow in order to introduce a delay between atrial and ventricular systole, which is due to the lack of connexin Cx43 expression and $\mathrm{Na}^{+}$channel Nav1.5. The upstroke of the nodal action potential is $\mathrm{Ca}^{2+}$ dependent, but instead of the myocardial L-type $\mathrm{Ca}^{2+}$ channel, Cav1.2, the alternative Cav1.3 is expressed, which has a more negative activation threshold, thus more appropriate for a $\mathrm{Ca}^{2+}$-dependent action potential. Data regarding the presence and distribution of $\mathrm{T}$ type $\mathrm{Ca}^{2+}$ channel is less consistent. Ion channel expression is plastic and may change with aging, heart failure, diabetes or athletic training (Boyett et al., 2009; Greener et al., 2011).

Neurohormonal stimuli have a significant role in the behavior of the AV node during atrial fibrillation. Sympathetic activity (increased sympathetic nerve activation or release of circulating catecholamines) acts via $\beta_{1}$-receptors/increased cAMP/protein kinase A activation, enhances the T-type $\mathrm{Ca}^{2+}$ and $I_{f}$ currents, increases the slope of diastolic depolarization (which plays no significant role during atrial fibrillation in the AV node), increases the rate and completeness of $I_{K}$ deactivation (which decreases the effective refractory periods, thus decreasing the efficacy of the filtering function of the AV node in AF). Parasympathetic stimuli act via $M_{2}$ muscarinergic receptors $/ G_{i}$ protein activation, which activate the $I_{K / A c h} \mathrm{~K}^{+}$current, leading to membrane hyperpolarization, and inhibition of $I_{C a} \mathrm{Ca}^{2+}$ and $I_{f} \mathrm{Na}^{+}$currents via reducing cAMP and protein kinase A activity (Boyett et al., 2009).

\section{Activation of the atrioventricular node in atrial fibrillation}

In sinus rhythm, the action potential enters the AV node via the penetrating bundle (and then passes to the ventricles) via a fast pathway (formed partly by the transitional zone) and a slow pathway (formed partly by the inferior nodal extension). During AF, the node is continuously bombarded from different directions with varying degrees of penetration. Propagation is dependent on the relative timing of the septal inputs to the AV node at the crista terminalis and interatrial septum, and also depends on atrial input frequency (Garrigue et al., 1999). The constant bombardment of atrial impulses creates varying degree 
of concealed conduction, when most stimuli enter the AV node but do not conduct to the ventricle, creating a wake of refractoriness encountered by subsequent impulses (Fujiki et al., 1990). This generally slows down the resulting ventricular rate, which becomes irregularly irregular. The atrial cycle length also changes continuously and may not be the same between different atrial regions (Duytschaever et al., 2001). As electrophysiological remodeling of the atrial myocardium occurs early during $\mathrm{AF}$, with changes in effective refractory period and excitability, the input signals arriving to the AV node may vary significantly. Results from experimental studies are heterogenous as various methods for AF induction have been used, that affect the resulting atrial electrical activity and atrioventricular conduction (Roka et al., 2008) (Figure 2). The randomness of the ventricular rhythm is still debated (van den Berg et al., 1995; Stein et al., 1999; Roka \& Merkely, 2008).

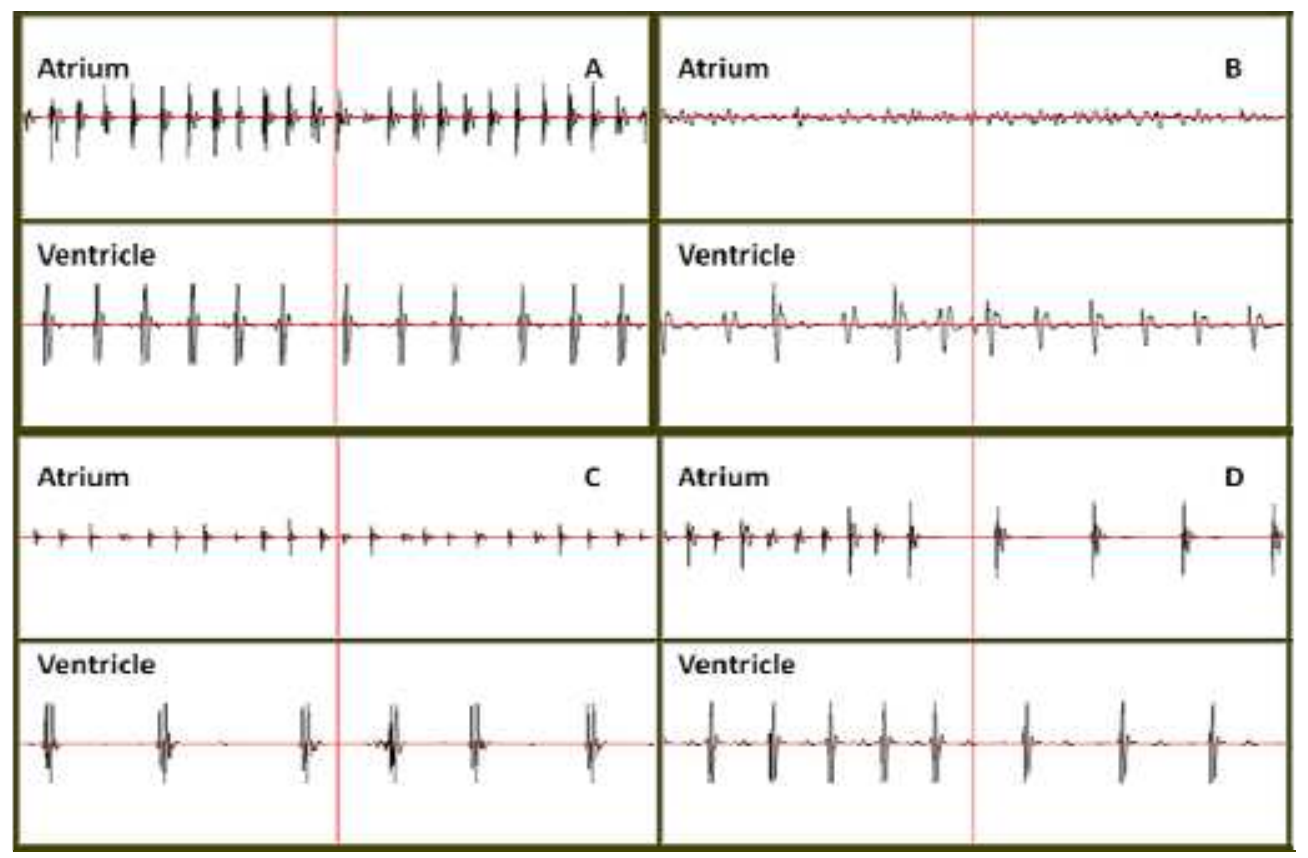

Fig. 2. Intracardiac recordings from healthy dogs with atrial fibrillation, induced by $50 \mathrm{~Hz}$ alternating current stimulation of the atria. Signals are recorded near the bundle of His (Ventricle) and near the AV node (Atrium). Atrial signal morphology is highly variable even in similar subjects with similar induction methods. A: discrete high frequency atrial signals with rapid, irregular ventricular rate. B: high frequency atrial signals without identifiable isoelectric baseline. C: discrete atrial signals with slower ventricular rate. D: spontaneous cardioversion of atrial fibrillation.

Main factors affecting the ventricular rate in AF are the electrophysiological properties of the AV node, rate and organization of atrial inputs, autonomic tone and effect of medications on the AV node. Increased parasympathetic and reduced sympathetic tone exert negative dromotropic effects on AV nodal conduction, while the opposite is true in states of decreased parasympathetic and increased sympathetic tone. Vagal tone also enhances the negative chronotropic effects of concealed conduction in the AV node (van den 
Berg et al., 1997). Fluctuations in autonomic tone can produce wide variations in ventricular rate - slow ventricular rate during sleep but accelerated ventricular response during exercise. Several other factors also play a significant role, such as exercise (Bootsma et al.,, 1970), retrograde conduction after premature or ventricular paced beats (Greenhut et al., 1996), drugs, age and gender (Hnatkova et al., 1998).

\section{Clinical relevance of $A V$ node function in atrial fibrillation}

If untreated, the ventricular rate is generally 90-170/minute in AF. Rates below 60/minute are seen with intrinsic AV node disease, high vagal tone or due to medications. Rates higher than 200/minute may be due to hyperthyroidism, presence of an accessory pathway or high catecholaminergic state. Regular ventricular rate during AF may indicate AV block with junctional or ventricular escape, or accelerated junctional activity. Occasionally, regularly irregular or group beating may be observed if the lower nodal pacemaker activity has a Wenckebach type exit block (Figure 3).

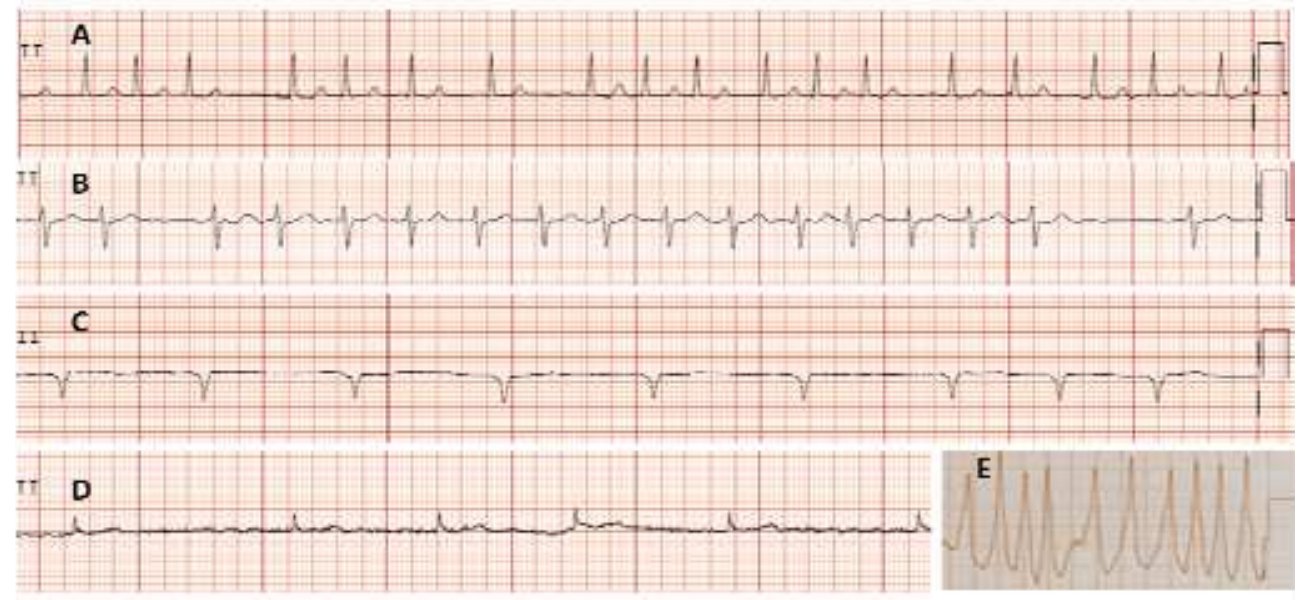

Fig. 3. Atrial fibrillation - variations of rate response. A: "typical" irregularly irregular rhythm. B: quasi-regular rhythm with occasional longer RR cycles. C: slow ventricular response, with junctional rhythm for most of the tracing. D: slow, irregular ventricular response. E: atrial fibrillation with preexcitation, "FBI tachycardia" - fast, broad, irregular.

A conventional 12-lead electrocardiogram is usually enough to establish the diagnosis. In paroxysmal forms Holter monitoring, event- or loop recording may be necessary (Fuster et al., 2011). In most cases, atrial fibrillation is easily diagnosed by the absence of $P$ waves, presence of $\mathrm{f}$ waves and irregularly irregular RR intervals. QRS complexes are narrow unless there is fixed or rate-dependent bundle-branch block or preexcitation. Aberrant conduction is common and facilitated by the irregularity of the ventricular response. When a long interval is followed by a relatively short interval, the QRS complex following the short interval is often aberrantly conducted (Ashman phenomenon). In case of severely decreased AV conduction, junctional escape may lead to a regular rhythm (Figure 4). This may be often observed with digoxin toxicity, due to impaired AV conduction and enhanced junctional automaticity. 


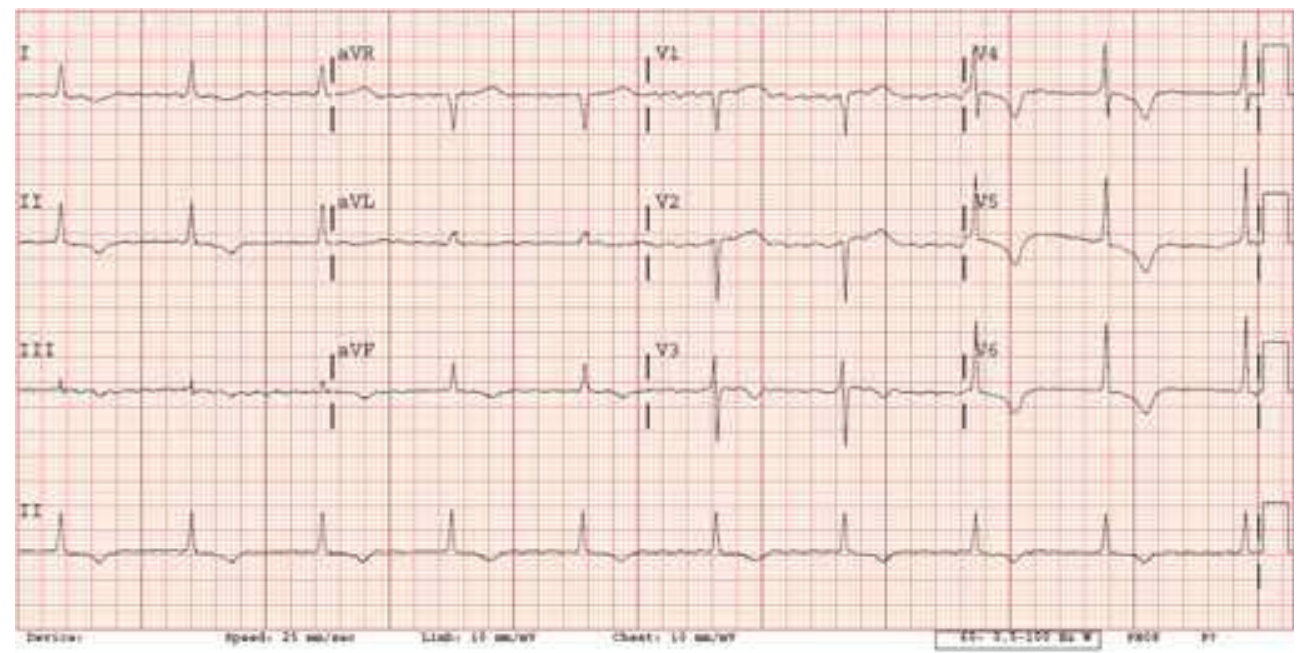

Fig. 4. Atrial fibrillation with junctional escape rhythm - the RR intervals are regular.

Atrial fibrillation may lead to irregular wide QRS tachycardia when it is associated with intraventricular conduction abnormalities, such as bundle branch block (Figure 5). Despite the irregular RR intervals, the QRS morphology shows little variation in these cases and is generally consistent with typical bundle branch block, occasionally showing ratedependency. The differential diagnosis should include atrial fibrillation with preexcitation (QRS morphology is variable, delta waves are present) and polymorphic ventricular tachycardia (highly variable QRS morphology usually not typical for bundle branch block, atrioventricular dissociation, fusion or capture beats may be visible).

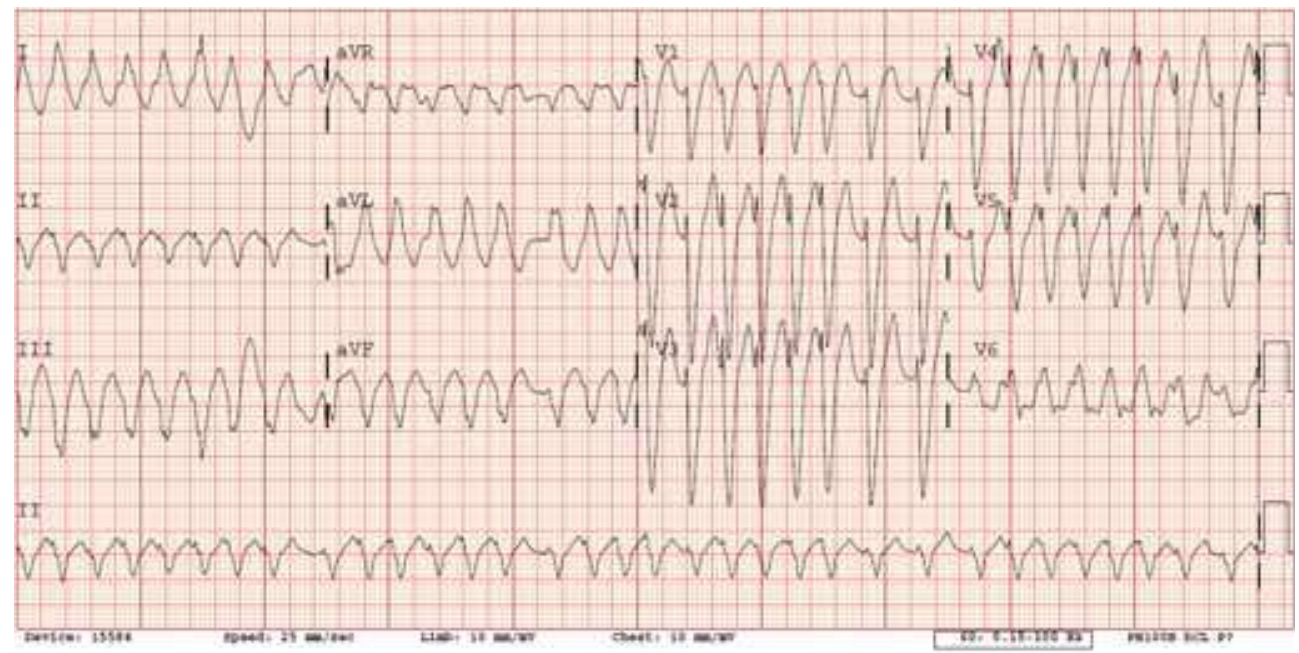

Fig. 5. Atrial fibrillation with rapid ventricular rate and left bundle branch block. 
Multiple supraventricular arrhythmias may mimic the irregularly irregular ventricular activation seen in $\mathrm{AF}$, either due to irregular atrial rate or variable atrioventricular conduction. Multifocal atrial tachycardia may be difficult to distinguish from atrial fibrillation if the P wave amplitude is low. In this case, each QRS should be preceded by a P wave, the atrioventricular delay may be slightly variable (Figure 6). In case of very high atrial rate or use of $\mathrm{AV}$-nodal blocking agents non-conducted $\mathrm{P}$ waves may be also observed.

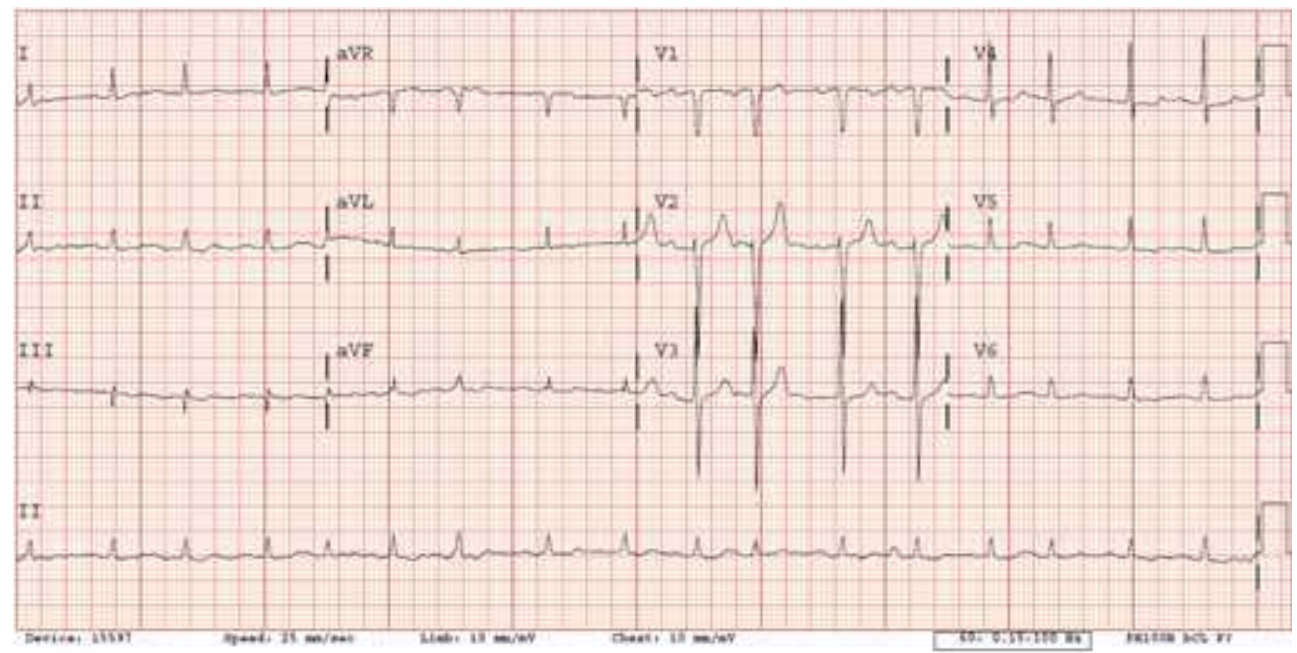

Fig. 6. Multifocal atrial tachycardia with irregularly irregular RR intervals similar to atrial fibrillation, however, each QRS is preceded by a P wave.

Atrial flutter may lead to irregular ventricular rate if the atrioventricular conduction does not follow a fixed ratio. Atypical flutters may lack the typical negative $F$ waves in the inferior leads (Figure 7). In certain cases, serial electrograms may show evidence of both atrial fibrillation and flutter in the same patient.

Occasionally, even sinus or atrial tachycardia may be difficult to distinguish from AF, if the $\mathrm{P}$ waves are hidden in the QRS-T complex due to high heart rate or prolonged atrioventricular delay and frequent premature beats lead to irregular rate.

Persistently elevated ventricular rate during AF may lead to tachycardia-induced cardiomyopathy. It is important to recognize this condition, in which heart failure is a consequence rather than the cause of $\mathrm{AF}$ as control of the ventricular rate may lead to reversal of the myopathic process (Grogan et al., 1992). The time and heart rate required to develop tachycardia-induced cardiomyopathy is less clear, however, heart rate above 130/minute seems to be necessary in most cases (Shinbane et al., 1997).

Irregular ventricular rate itself decreases the cardiac output (Clark et al., 1997) and coronary blood flow (Wichmann et al., 1983). Myocardial contractility is not constant during AF because of force-interval relationships associated with variations in cycle length, this contributes to the largely variable pulse pressures and stroke volumes (Brookes et al., 1998). 


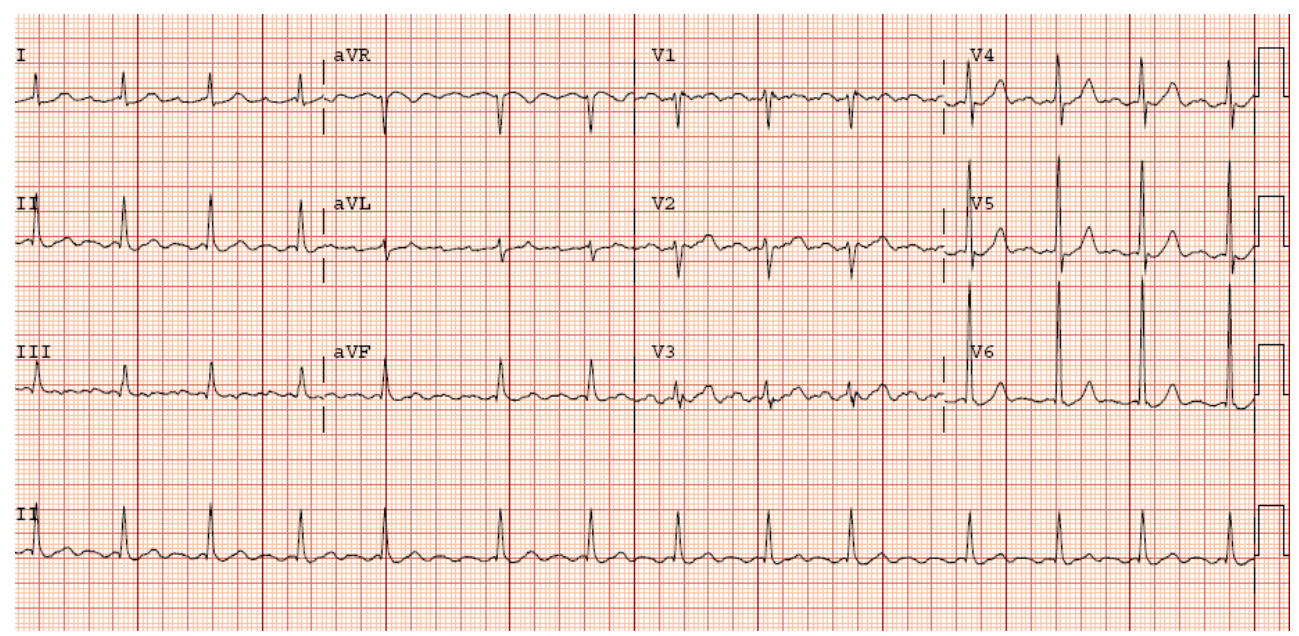

Fig. 7. Atypical atrial flutter with irregular RR intervals due to variable atrioventricular conduction.

Rapid ventricular rate during AF may adversely impact mitral valve function, increasing mitral regurgitation, due to the relationship between left atrial and left ventricular pressures. In addition, rate-related intraventricular conduction delay (such as left bundlebranch block) may further compromise the synchrony of LV wall motion and reduce cardiac output. Such conduction disturbances may further exacerbate mitral regurgitation and limit ventricular filling. Controlling the ventricular rate and regularity may reverse these adverse hemodynamic effects, however, the changes can persist for a prolonged time even after cardioversion (Upshaw, 1997). Tachycardia-induced cardiomyopathy tends to resolve within 6 months of rate or rhythm control; when tachycardia recurs, LV ejection fraction declines and HF develops over a shorter period, this is associated with a relatively poor prognosis (Nerheim et al., 2004). Although it would be clinically important to identify patients where high ventricular rate plays the major role in the development of heart failure, thus may benefit from aggressive rate and/or rhythm control, prospective identification of these cases is difficult, so far heart failure associated with relatively small left ventricular size seems to be predictive (Fujino et al., 2007).

\section{Pharmacological rate control}

Several complications of atrial fibrillation are due to high, irregular ventricular rate: palpitations, heart failure, and tachycardia-induced cardiomyopathy. The ventricular rate may increase excessively during exercise even when it is well controlled at rest. Medications used to control ventricular rate generally work by increasing the refractory period of the $I_{c a, L}$ $\mathrm{Ca}^{+}$current, thus increasing the filtering function of the AV node. Non-dihydropyridine (non-DHP) calcium channel inhibitors, such as verapamil and diltiazem, directly inhibit the $I_{c a}, L$, while adrenergic $\beta$-blockers work indirectly through the adrenergic receptors. Digoxin increases parasympathetic vagal activity and is ineffective in situations when vagal tone diminishes, such as exercise. Antiarrhythmic medications, such as amiodarone or dronedarone may also be used for rate control due to their pluripotent effects. When $\mathrm{Na}^{+}$ channel blockers are used for cardioversion or maintenance of sinus rhythm, increase in 
ventricular rate may occasionally be observed due to vagolytic effects (quinidine, disopyramide) or regularization of atrial activity (such as atrial flutter), which in turn decreases the filtering effect of concealed conduction. Adenosine binds to A1 receptors and activates $I_{K / A d o}$, a subtype of $I_{k}$ similar to $I_{K / A c h}$ increasing outward $\mathrm{K}^{+}$current, similar to parasympathetic stimuli; it also inhibits $I_{f}$.

The definition of adequate rate control has been based primarily on short-term hemodynamic studies and mostly refers to ventricular rate below a certain limit, but has not been well studied with respect to regularity of the ventricular response. Initial rate control criteria varied with patient age, usually involved achieving ventricular rates between 60$80 /$ minute at rest and between 90-115/minute during moderate exercise. For the AFFIRM trial, adequate control was defined as an average heart rate up to $80 /$ minute at rest and either an average rate up to 100/minute over at least 18 hour ambulatory Holter monitoring with no rate above $100 \%$ of the maximum age-adjusted predicted exercise heart rate or a maximum heart rate of 110/ minute during a 6-minute walk test (Olshansky et al., 2004). The RACE trial used heart rate less than 100/minute at rest. In the rate control arm, no differences were observed in terms of cardiovascular morbidity, mortality, and quality of life between the patients who achieved resting heart rate $<80 /$ minute, compared to those with higher resting heart rate (Groenveld et al., 2009). A comparison of the rate control arms of the AFFIRM and RACE studies (mean heart rate 76.1 vs. 83.4/minute) showed no significant difference in the primary composite endpoint of mortality, cardiovascular hospitalization and myocardial infarction. However, patients with mean heart rates during AF within the AFFIRM $(\leq 80 /$ minute) or RACE ( $<100 /$ minute) criteria had a better outcome than patients with heart rates $\geq 100$ /minute (hazard ratios 0.69 and 0.58 , respectively, for $\leq 80 /$ minute and $<100 /$ minute compared with $\geq 100$ / minute, van Gelder et al., 2006).

The large randomized, prospective RACE II trial compared lenient rate-control (resting heart rate $<110 /$ minute) vs. strict rate-control strategy (resting heart rate $<80 /$ minute and heart rate during moderate exercise $<110 /$ minute), in 614 patients with permanent atrial fibrillation. The primary outcome was a composite of death from cardiovascular causes, hospitalization for heart failure, and stroke, systemic embolism, bleeding, and lifethreatening arrhythmic events. The duration of follow-up was at least 2 years, with a maximum of 3 years. The estimated cumulative incidence of the primary outcome at 3 years was $12.9 \%$ in the lenient-control group and $14.9 \%$ in the strict-control group $(p<0.001$ for the prespecified non-inferiority margin). The frequencies of the components of the primary outcome were similar in the two groups. More patients in the lenient-control group met the target heart rate: $97.7 \%$ vs. $67.0 \%(p<0.001)$, with fewer total visits (median 0 vs. 2 per patient, $\mathrm{p}<0.001)$. The frequencies of symptoms and adverse events were similar in the two groups (van Gelder et al., 2010). The study population was $66 \%$ male with an average age of $68 \pm 8$ years, body mass index of $29 \pm 5$, left ventricular ejection fraction of $52 \pm 12 \%, 65 \%$ in NYHA functional class I. Lenient rate control with a resting heart rate $<110 /$ minute may be adequate for these patients. Patients with moderate to severe heart failure were underrepresented in this study (NYHA III in $4.7 \%$, left ventricular ejection fraction $<40 \%$ in $15 \%$ of patients), the optimal heart rate for these patients is less clear.

The clinical outcomes (mortality, morbidity), that can be achieved with focusing on rate control and anticoagulation were similar to those with aggressive rhythm control using antiarrhythmic drugs and cardioversion in the large randomized AFFIRM and RACE trials (Olshansky et al., 2004; Hagens et al., 2005). However, this may be due to the relative inefficacy and poor side effect profile of current antiarrhythmic medications and may 
change in the near future as new medications are developed and indications of atrial fibrillation ablation evolve. Patients who actually stayed in sinus rhythm in the AFFIRM trial, independent of treatment strategy, had better outcomes (Corley et al., 2004).

The practice guidelines on the management of atrial fibrillation, including rate control, have recently been updated by the American College of Cardiology Foundation, American Heart Association, and, and the European Society of Cardiology (Fuster et al., 2011, Table 1 and 2).

\begin{tabular}{|c|c|c|}
\hline Recommendations & $\begin{array}{c}\text { Class of } \\
\text { recommendation }\end{array}$ & $\begin{array}{l}\text { Level of } \\
\text { evidence }\end{array}$ \\
\hline \multicolumn{3}{|l|}{ General } \\
\hline Measurement of the heart rate at rest & $\mathrm{I}$ & B \\
\hline $\begin{array}{l}\text { In patients with AF-related symptoms during activity, heart rate } \\
\text { control should be assessed during exercise }\end{array}$ & $\mathrm{I}$ & B \\
\hline $\begin{array}{l}\text { Use of pharmacological rate control for persistent of permanent } \\
\mathrm{AF}\end{array}$ & I & B \\
\hline \multicolumn{3}{|l|}{ Acute setting } \\
\hline $\begin{array}{l}\text { Iv. beta-blocker or non-DHP calcium channel antagonist to slow } \\
\text { down ventricular rate (caution in hypotensive patients) }\end{array}$ & I & B \\
\hline $\begin{array}{l}\text { Iv. digoxin or amiodarone for patients with } \mathrm{AF} \text { and heart } \\
\text { failure, without preexcitation }\end{array}$ & $\mathrm{I}$ & B \\
\hline $\begin{array}{l}\text { Iv. amiodarone when other measures are unsuccessful or } \\
\text { contraindicated }\end{array}$ & IIa & $\mathrm{C}$ \\
\hline $\begin{array}{l}\text { Iv. procainamide or ibutilide in } \mathrm{AF} \text { with preexcitation, if } \\
\text { electrical cardioversion is not indicated }\end{array}$ & IIa & $\mathrm{C}$ \\
\hline $\begin{array}{l}\text { Iv. procainamide, disopyramide, ibutilide, or amiodarone for } \\
\text { hemodynamically stable AF with accessory pathway }\end{array}$ & $\mathrm{IIb}$ & B \\
\hline \multicolumn{3}{|l|}{$\begin{array}{ll}\text { Chronic pharmacological rate control } \\
\end{array}$} \\
\hline $\begin{array}{l}\text { Oral digoxin for rate control at rest in patients with HF, LV } \\
\text { dysfunction, or sedentary lifestyle }\end{array}$ & $\mathrm{I}$ & $\mathrm{C}$ \\
\hline $\begin{array}{l}\text { Oral digoxin + beta blocker or non-DHP calcium channel } \\
\text { antagonist for rate control at rest and during exercise. } \\
\text { Medication choice and doses should be individualized to avoid } \\
\text { bradycardia. }\end{array}$ & IIa & B \\
\hline $\begin{array}{l}\text { Oral amiodarone alone or in combination if adequate rate } \\
\text { cannot at rest and during exercise cannot be achieved with beta- } \\
\text { blocker, non-DHP calcium channel antagonist, or digoxin }\end{array}$ & $\mathrm{IIb}$ & C \\
\hline \multicolumn{3}{|l|}{ Non-pharmacological rate control } \\
\hline $\begin{array}{l}\text { Ablation of the AV node or accessory pathway when } \\
\text { pharmacological therapy is insufficient or associated with side } \\
\text { effects }\end{array}$ & IIa & B \\
\hline $\begin{array}{l}\text { Catheter ablation of the AV node if rate control cannot be } \\
\text { achieved by pharmacological agents or tachycardia-mediated } \\
\text { cardiomyopathy is suspected }\end{array}$ & $\mathrm{IIb}$ & $\mathrm{C}$ \\
\hline
\end{tabular}

Table 1. Recommended procedures and interventions for ventricular rate control in atrial fibrillation. Levels of recommendation: class I - generally recommended. Class IIa - should be considered. Class IIb - may be considered. Levels of evidence: B - single randomized trial or nonrandomized studies. C - consensus opinion of experts, case studies or standard of care. AF: atrial fibrillation. DHP: dihydropyridine. Iv.: intravenous. HF: heart failure. LV: left ventricular. $A V$ : atrioventricular. 


\begin{tabular}{|l|c|c|}
\hline \multicolumn{1}{|c|}{ Contraindicated procedures and interventions } & $\begin{array}{c}\text { Class of } \\
\text { recommendation }\end{array}$ & $\begin{array}{c}\text { Level of } \\
\text { evidence }\end{array}$ \\
\hline Digoxin alone in paroxysmal atrial fibrillation & III & B \\
\hline $\begin{array}{l}\text { Catheter ablation of the AV node without prior attempt of } \\
\text { pharmacological rate control }\end{array}$ & III \\
\hline Iv. non-DHP calcium channel antagonist in decompensated HF & III & C \\
\hline $\begin{array}{l}\text { Iv. digoxin or non-DHP calcium channel antagonist in AF with } \\
\text { preexcitation }\end{array}$ & III & C \\
\hline
\end{tabular}

Table 2. Contraindicated procedures and interventions for ventricular rate control in atrial fibrillation. Levels of recommendation: class III - generally contraindicated as there is no benefit or may be harmful. Levels of evidence: B - single randomized trial or nonrandomized studies. C - consensus opinion of experts, case studies or standard of care. AF: atrial fibrillation. DHP: dihydropyridine. Iv.: intravenous. HF: heart failure. LV: left ventricular. $A V$ : atrioventricular.

\subsection{Acute rate control}

Patients who are symptomatic with rapid ventricular rates during AF require prompt medical management, and cardioversion should be considered if symptomatic hypotension, angina, or heart failure is present. The pharmacological agent of choice depends on the presence of comorbidities, such as heart failure/hemodynamic instability and preexcitation (Fuster et al., 2011; Table 3).

\begin{tabular}{|c|c|c|c|}
\hline Medication & Dose in acute setting & $\begin{array}{c}\text { Class of } \\
\text { recommendation }\end{array}$ & $\begin{array}{l}\text { Level of } \\
\text { evidence }\end{array}$ \\
\hline \multicolumn{4}{|c|}{ No heart failure or accessory pathway } \\
\hline Esmolol & $\begin{array}{c}500 \mu \mathrm{g} / \mathrm{kg} \text { slow iv. bolus, } 60-200 \mu \mathrm{g} / \mathrm{kg} / \mathrm{min} \\
\text { infusion }\end{array}$ & I & $\mathrm{C}$ \\
\hline Metoprolol & 2.5-5 mg slow iv. bolus & $\mathrm{I}$ & $\mathrm{C}$ \\
\hline Diltiazem & $\begin{array}{l}0.25 \mathrm{mg} / \mathrm{kg} \text { slow iv. bolus, } 5-15 \mathrm{mg} / \mathrm{h} \\
\text { infusion }\end{array}$ & I & B \\
\hline Verapamil & $75-150 \mu \mathrm{g} / \mathrm{kg}$ slow iv. bolus & I & B \\
\hline \multicolumn{4}{|c|}{ Heart failure } \\
\hline Digoxin & $\begin{array}{l}0.25 \mathrm{mg} \text { iv. every } 2 \text { hours, up to } 1.5 \mathrm{mg} \text {; } \\
\text { followed by } 0.125-0.375 \mathrm{mg} / \text { day iv. or po., } \\
\text { slow onset of action }\end{array}$ & I & B \\
\hline Amiodarone & $\begin{array}{c}150 \mathrm{mg} \text { iv. over } 10 \text { minutes, } 0.5-1 \mathrm{mg} / \mathrm{min} \\
\text { infusion }\end{array}$ & IIIa & $\mathrm{C}$ \\
\hline \multicolumn{4}{|c|}{ Accessory pathway } \\
\hline Amiodarone & $\begin{array}{c}150 \mathrm{mg} \text { iv. over } 10 \text { minutes, } 0.5-1 \mathrm{mg} / \mathrm{min} \\
\text { infusion }\end{array}$ & IIa & $\mathrm{C}$ \\
\hline \multicolumn{4}{|c|}{ Accessory pathway and heart failure } \\
\hline- & Urgent electrical cardioversion & $\mathrm{I}$ & $\mathrm{B}$ \\
\hline
\end{tabular}

Table 3. Recommendations for acute rate control in atrial fibrillation. Instead of esmolol and metoprolol, similar beta-blocking agents may be used with same class of recommendation. Levels of recommendation: class I - generally recommended. Class IIa - should be considered. Levels of evidence: B - single randomized trial or nonrandomized studies. C consensus opinion of experts, case studies or standard of care. Iv.: intravenous.

Intravenous non-DHP calcium channel antagonists are effective for ventricular rate control (Boudonas et al., 1995), although these agents should be avoided in patients with 
heart failure due to systolic dysfunction because of their negative inotropic effects. A randomized trial comparing intravenously administered diltiazem, digoxin and amiodarone found that patients presenting to the emergency department with AF and heart rate $>120 / \mathrm{min}$ achieved shorter time to rate control (rate $<90 /$ minute), largest reduction in AF symptom frequency and severity scores and significantly shorter hospital stay if they were assigned to the diltiazem group, versus digoxin or amiodarone (Siu et al., 2009). Beta blockers may be particularly useful in states of high adrenergic tone, such as postoperative AF, but more data is available for rhythm control in this situation: intravenous esmolol produced more rapid conversion to sinus rhythm than diltiazem after noncardiac surgery, ventricular rates after 2 and 12 hours were similar with both treatments (Balser et al., 1998).

Combinations may be necessary to achieve rate control, which requires careful dose titration. Although intravenous digoxin may slow down the ventricular response in AF at rest, the onset is delayed for at least 60 minutes in most patients and the peak effect does not develop for up to 6 hours. There is lack of evidence whether a second agent should be added early (to avoid possible dose-related side effects of medications) or only after administration the maximum recommended dose of the first agent. Wide variations in clinical practice exist, however, the outcomes were similar in observational studies (Buccelletti et al., 2011; Stiell et al., 2011).

\subsection{Chronic rate control}

There is no evidence that long-term pharmacological rate control would adversely influence left ventricular function, although bradycardia and heart block may occur as an unwanted effect of beta blockers, amiodarone, digoxin, or non-DHP calcium channel antagonists. Elderly patients and those with paroxysmal AF are more likely to experience side effects. Some patients develop symptomatic bradycardia that requires permanent pacing, while still having episodes of rapid ventricular rate. Non-pharmacological therapy should be considered when pharmacological measures fail.

Beta-blockers are safe and effective for rate control and superior to placebo. They should be initiated cautiously in patients with heart failure who have reduced ejection fraction. Most data are available for nadolol and atenolol. Patients may experience slow rates at rest, or exercise tolerance may be compromised when the rate response is blunted excessively (Segal et al., 2000). Sotalol, in addition to its antiarrhythmic effects, also provides excellent rate control (Anderson \& Prystowsky, 1999). Atenolol, metoprolol, and sotalol provide better control of exercise-induced tachycardia than digoxin (Lewis et al., 1989). Carvedilol is similarly effective. Beta blockers were the most effective drug class for rate control in the AFFIRM trial (with or without digoxin), achieving rate control endpoints in $70 \%$ of patients, compared to $54 \%$ with use of calcium channel blockers (Olshansky et al., 2004).

Non-DHP calcium channel antagonist agents (verapamil and diltiazem) are the only agents that were shown to improve quality of life and exercise tolerance. Direct comparisons of verapamil and diltiazem have demonstrated similar effectiveness (Lundström \& Rydén, 1990). These agents may be preferred for long-term use over beta blockers in patients with bronchospasm or chronic obstructive pulmonary disease.

The efficacy of digoxin is reduced in states of high sympathetic tone or in paroxysmal AF. The combination of digoxin and atenolol is effective for rate control (Farshi et al., 1999). In contrast to its limited effect in patients with paroxysmal AF, digoxin is moderately effective 
in those with persistent AF, particularly when HF is present. Digoxin administered alone slows the resting heart rate, but it does not slow heart rate during exercise (Segal et al., 2000). Given the multiple interactions and side effects, digoxin should not be considered as first line therapy for rate control. The combination of digoxin and a beta blocker appears more effective than the combination of digoxin with a calcium channel antagonist (Farshi et al., 1999).

Amiodarone has both sympatholytic and calcium antagonist properties, which depresses $\mathrm{AV}$ conduction. Intravenous amiodarone is generally well tolerated in critically ill patients who develop rapid atrial tachyarrhythmias refractory to conventional treatment, but efficacy has not been sufficiently evaluated in this indication. It may be considered when first line agents are ineffective or contraindicated (Clemo et al., 1998). The potential toxicity must be carefully weighted (Fuster et al., 2011, Table 4).

\begin{tabular}{|c|c|c|c|}
\hline Medication & Maintenance dose & $\begin{array}{c}\text { Class of } \\
\text { recommendation }\end{array}$ & $\begin{array}{l}\text { Level of } \\
\text { evidence }\end{array}$ \\
\hline \multicolumn{4}{|c|}{ No heart failure or accessory pathway } \\
\hline Metoprolol & $25-100 \mathrm{mg}$ twice a day & I & $\mathrm{C}$ \\
\hline Diltiazem & $\begin{array}{c}\text { 120-360 mg daily, divided doses or slow } \\
\text { release }\end{array}$ & $\mathrm{I}$ & B \\
\hline Verapamil & $\begin{array}{l}\text { 120-360 mg daily, divided doses or slow } \\
\text { release }\end{array}$ & $\mathrm{I}$ & $\mathrm{B}$ \\
\hline \multicolumn{4}{|c|}{ Heart failure, no accessory pathway } \\
\hline Digoxin & $\begin{array}{l}0.5 \mathrm{mg} \text { po. loading, } 0.125-0.375 \mathrm{mg} / \text { day po. } \\
\text { maintenance; slow onset of action ( } 2 \text { days) }\end{array}$ & $\mathrm{I}$ & $\mathrm{C}$ \\
\hline Amiodarone & $\begin{array}{c}800 \mathrm{mg} \text { daily for } 1 \text { week, } 600 \mathrm{mg} \text { daily for } 1 \\
\text { week, } 400 \mathrm{mg} \text { daily for } 4-6 \text { week, maintenance } \\
200 \mathrm{mg} \text { po. daily; slow onset of action (1-3 } \\
\text { weeks) }\end{array}$ & $\mathrm{IIb}$ & $\mathrm{C}$ \\
\hline \multicolumn{4}{|c|}{ Accessory pathway } \\
\hline- & Ablation should be considered & - & - \\
\hline
\end{tabular}

Table 4. Recommendations for chronic rate control in atrial fibrillation. Instead of metoprolol, similar beta-blocking agents may be used with same class of recommendation. Levels of recommendation: class I - generally recommended. Class IIb - may be considered. Levels of evidence: B - single randomized trial or nonrandomized studies. C - consensus opinion of experts, case studies or standard of care. po.: oral.

Oral amiodarone decreases the ventricular rate without affecting exercise capacity, quality of life or AF symptoms, even if it is unable to cardiovert the patient (Tse et al., 2001). Dronedarone has also good rate control characteristics in addition to its antiarrhythmic effects, with a side effect profile more favorable than amiodarone (Page et al., 2011). However, excess mortality and morbidity in elderly patients with permanent AF lead to early discontinuation of the PALLAS trial, so dronaderone is contraindicated in permanent AF.

In patients with paroxysmal atrial flutter and fibrillation, propafenone or flecainide used for rhythm control may promote 1:1 AV conduction during the flutter, leading to excessive ventricular rate. These agents must be coadministered with AV nodal blocking agents, unless ablation has been performed without recurrence of the flutter. 


\section{Non-pharmacological rate control}

The efficacy of pharmacological interventions designed to achieve rate control in patients with AF has been about $80 \%$ in clinical trials (Weerasooriya et al., 2003). Nonpharmacological measures should be considered in patients who are still symptomatic or in whom adequate rate control cannot be achieved.

Ventricular pacing at approximately the mean ventricular rate during AF may regularize the ventricular rhythm during AF by eliminating longer ventricular cycles and reducing the number of short ventricular cycles due to retrograde block (Wittkampf et al., 1988). This may be useful for patients with marked variability in ventricular rates or resting bradycardia during pharmacological treatment. However, frequent right ventricular pacing may lead to left ventricular dysfunction. Patients with paroxysmal AF indicated a preference for the paced regularization strategy in a study, while patients with permanent AF showed no preference despite a 29\% improvement of irregularity (Simpson et al., 2001). However, another study showed no benefit in any group (Tse et al., 2004).

AV node ablation in conjunction with permanent pacemaker implantation provides effective control of the heart rate and improves symptoms in selected patients with AF. Patients most likely to benefit from this strategy are those with symptoms or tachycardia mediated cardiomyopathy related to rapid ventricular rate during $\mathrm{AF}$, that cannot be controlled adequately with antiarrhythmic or negative chronotropic medications (Wood et al., 2000). In the Ablate and Pace Trial, 25\% of patients with AF who had an ejection fraction below 45\% displayed a greater than 15\% increase in ejection fraction after ablation (Kay et al., 1998).

The slow pathway of the AV node has a short effective refractory period that may be responsible for maintaining rapid ventricular rate during AF. Catheter ablation of this area (inferior atrial inputs to the AV node) slows the ventricular rate during AF and improves symptoms without pacemaker implantation (Williamson et al., 1995). However, the ventricular rate rises over the 6 months following ablation.

Complete AV nodal ablation and permanent pacemaker implantation demonstrated better symptom relief than AV node modification alone. The 1-year mortality rate after AV nodal ablation and permanent pacemaker implantation is approximately $6.3 \%$, with $2.0 \%$ risk of sudden death. Although a causal relationship between the procedure and sudden death still remains controversial, the pacemaker is routinely set to a high basic rate, such as $90 /$ minute for the first month after ablation, to avoid bradycardia-induced tachyarrhythmias after a prolonged period of rapid ventricular rate (Evans et al., 1991). Although the symptomatic benefits of $\mathrm{AV}$ nodal ablation are clear, limitations include the persistent need for anticoagulation, loss of AV synchrony, and lifelong pacemaker dependency.

As the adverse hemodynamic effects of right ventricular apical pacing are well known, biventricular devices should be considered in these patients, especially in those with left ventricular dysfunction or heart failure. The PAVE trial showed better exercise tolerance with biventricular pacing, but no mortality benefit was realized over the relatively short follow up period of 6 months (Doshi et al., 2005). A subgroup analysis suggested that functional improvements were confined to patients with left ventricular ejection fraction below $35 \%$ before ablation. Upgrade to a biventricular device should be considered after AV node ablation in patients with heart failure and a right ventricular pacing system (Leon et al., 2002). 
In patients with heart failure and $\mathrm{AF}$, undergoing cardiac resynchronization therapy, ablation of the AV node should be considered as rapid ventricular rate may lead to suboptimal biventricular stimulation. Biventricular stimulation should be at least $98 \%$ to achieve optimal benefits from resynchronization, which may be difficult to achieve in AF without AV node ablation (Hayes et al., 2011; Figure 8). In addition, the irregular rhythm alone adversely affects the hemodynamic function.

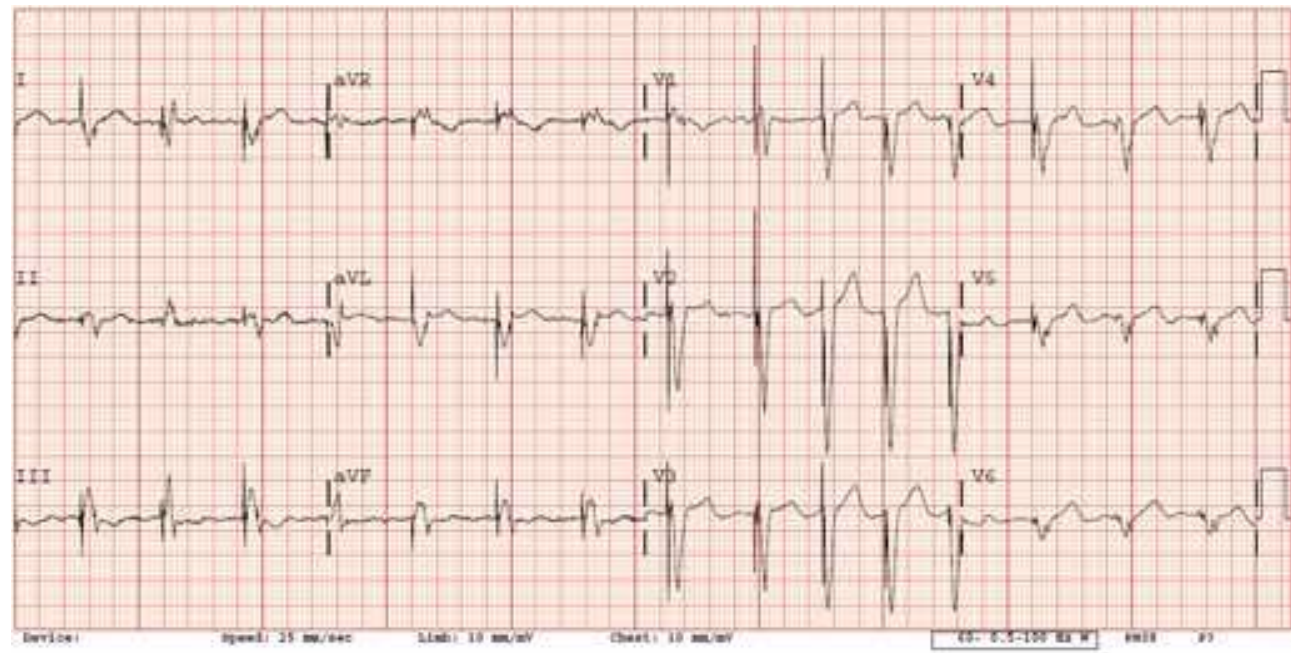

Fig. 8. Importance of rate control in patients with cardiac resynchronization devices. These devices improve hemodynamics in patients with severe left ventricular dysfunction and intraventricular conduction delay by simultaneously pacing the right and left ventricle. In case the ventricles get activated before the delivery of the pacing stimuli, such as in atrial fibrillation with suboptimal rate control, the only option left for the device is to pace simultaneously with the sensed beat (sense response pacing). However, this fusion beat may be hemodynamically inferior to the biventricular paced beat. In addition, irregularity of the rhythm adds to the hemodynamic derangement.

Parasympathetic nerve stimulation is an experimental method to achieve rate control via selective stimulation of the parasympathetic nerves supplying the AV node. This may be accomplished with a coronary sinus electrode or an active fixation electrode positioned near the AV node (Vago et al., 2004). This method may be an option in the future for patients with highly symptomatic paroxysmal atrial fibrillation, when medications or ablation are not desired, tolerated or effective. However, in some cases, atrial fibrillation may be vagally mediated and this method of stimulation may potentially increase the incidence of arrhythmias or increase the duration of the episodes.

\section{Preexcitation in atrial fibrillation}

A bypass tract with non-decremental conduction and short effective refractory period may allow the almost unfiltered propagation of AF to the ventricles, resulting in an extremely high ventricular rate, even $>300 /$ minute. Variable QRS morphology and irregular rate may 
be useful clues for identification and differentiation from ventricular tachycardia. Prompt recognition and treatment is important as this entity may rapidly degenerate to ventricular fibrillation (Fuster V., 2011). In hemodynamically stable patients with preexcitation, type I antiarrhythmic agents or amiodarone may be administered intravenously. AV nodal blocking drugs are contraindicated as the heart rate increases when the ventricles are activated solely through the bypass tract. The potential for beta blockers to facilitate conduction across the accessory pathway is controversial. In unstable cases, prompt electrical cardioversion is the treatment of choice. Beta blockers and calcium channel blockers may be considered for chronic oral use (Petri et al., 1983).

\section{Conclusion}

Ventricular rate in atrial fibrillation is determined by a complex interaction between the atrial electrical activity and properties of the AV node. Although the hemodynamic consequences of the rapid and irregular ventricular rate are well known, details of electropathophysiology still need to be elucidated.

Rate control is one of the most important aspects in the treatment of patients with atrial fibrillation, with substantial evidence supporting the use of pharmacological agents in both acute and chronic settings. Effective non-pharmacological treatment options may be used in refractory cases.

\section{Acknowledgments}

Dr. Erika Toth's contribution to the manuscript is appreciated.

The publication was supported by TAMOP 4.2.2-08/1/KMR-2008-0004, TAMOP-4.2.1.B09/1/KMR and TAMOP 4.2.2./B10/1.-2010-0013 grants provided by the National Development Agency of Hungary.

\section{References}

Anderson, J.L. \& Prystowsky, E.N. (1999). Sotalol: An important new antiarrhythmic. Am Heart el, Vol. 137, No. 3, pp. 388-409.

Bakker, M.L., Christoffels, V.M. \& Moorman, A.F.M. (2010). The cardiac pacemaker and conduction system develops from embryonic myocardium that retains its primitive phenotype. JCardiovasc Pharmacol, Vol. 56, No. 1, pp. 6-15.

Balser, J.R., Martinez, E.A., Winters, B.D., Perdue, P.W., Clarke, A.W., Huang, W., Tomaselli, G.F., Dorman, T., Campbell, K., Lipsett, P., Breslow, M.J. \& Rosenfeld, B.A. (1998). Beta-adrenergic blockade accelerates conversion of postoperative supraventricular tachyarrhythmias. Anesthesiology, Vol. 89, No. 5, pp. 1052-1059.

Bootsma, B.K., Hoelen, A.J., Strackee, J. \& Meijler, F.L. (1970). Analysis of R-R intervals in patients with atrial fibrillation at rest and during exercise. Circulation, Vol. 41, No. 5, pp. 783-794.

Boudonas, G., Lefkos, N., Efthymiadis, A.P., Styliadis, I.G. \& Tsapas, G. (1995). Intravenous administration of diltiazem in the treatment of supraventricular tachyarrhythmias. Acta Cardiol, Vol. 50, No. 3, pp. 125-134.

Boyett, M.R. (2009). 'And the beat goes on' The cardiac conduction system: the wiring system of the heart. Exp Physiol, Vol. 94, No. 10, pp. 1035-1049. 
Brookes, C.I., White, P.A., Staples, M., Oldershaw, P.J., Redington, A.N., Collins, P.D., Noble, M.I. (1998). Myocardial contractility is not constant during spontaneous atrial fibrillation in patients. Circulation, Vol. 98, No. 17, pp. 1762-1768.

Buccelletti, F., Di Somma, S., Galante, A., Pugliese, F., Alegiani, F., Bertazzoni, G., Silveri, N.G., Legramante, J.M. \& Franceschi, F. (2011). Disparities in management of newonset atrial fibrillation in the emergency department despite adherence to the current guidelines: data from a large metropolitan area. Intern Emerg Med, Vol. 6, No. 2, pp. 149-156.

Clark, D.M., Plumb, V.J., Epstein, A.E. \& Kay, G.N. (1997). Hemodynamic effects of an irregular sequence of ventricular cycle lengths during atrial fibrillation. JAm Coll Cardiol, Vol. 30, No. 4, pp. 1039-1045.

Clemo, H.F., Wood, M.A., Gilligan, D.M. \& Ellenbogen K.A. (1998). Intravenous amiodarone for acute heart rate control in the critically ill patient with atrial tachyarrhythmias. Am JCardiol, Vol. 81, No. 5, pp. 594-598.

Corley, S.D., Epstein, A.E., DiMarco, J.P., Domanski, M.J., Geller, N., Greene, H.L., Josephson, R.A., Kellen, J.C., Klein, R.C., Krahn, A.D., Mickel, M., Mitchell, L.B., Nelson, J.D., Rosenberg, Y., Schron, E., Shemanski, L., Waldo, A.L., Wyse, D.G. \& AFFIRM Investigators. (2004). Relationships between sinus rhythm, treatment, and survival in the Atrial Fibrillation Follow-Up Investigation of Rhythm Management (AFFIRM) Study. Circulation, Vol. 109, No. 12, pp. 1509-1513.

Doshi, R.N., Daoud, E.G., Fellows, C., Turk, K., Duran, A., Hamdan, M.H., Pires, L.A. \& PAVE Study Group. (2005). Left ventricular-based cardiac stimulation post AV nodal ablation evaluation (the PAVE study). JCadiovasc Electrophysiol, Vol. 16, No. 11, pp. 1160-1165.

Duytschaever, M., Mast, F., Killian, M., Blaauw, Y., Wijffels, M. \& Allessie, M. (2001). Methods for determining the refractory period and excitable gap during persistent atrial fibrillation in the goat. Circulation, Vol. 104, No. 8, pp. 957-962.

Evans, G.T.Jr., Scheinman, M.M., Bardy, G., Borggrefe, M., Brugada, P., Fisher, J., Fontaine, G., Huang, S.K., Huang, W.H. \& Josephson, M. (1991). Predictors of in-hospital mortality after DC catheter ablation of atrioventricular junction. Results of a prospective, international, multicenter study. Circulation, Vol. 84, No. 5, pp. 19241937.

Farshi, R., Kistner, D., Sarma, J.S., Longmate, J.A. \& Singh, B.N. (1999). Ventricular rate control in chronic atrial fibrillation during daily activity and programmed exercise: a crossover open-label study of five drug regimens. JAm Coll Cardiol, Vol. 33, No. 2, pp. 304-310.

Fujiki, A., Tani, M., Mizumaki, K., Yoshida, S. \& Sasayama S. (1990). Quantification of human concealed atrioventricular nodal conduction: relation to ventricular response during atrial fibrillation. Am Heart el Vol. 120, No. 3, pp. 598-603.

Fujino, T., Yamashita, T., Suzuki, S., Sugiyma, H., Sagara, K., Sawada, H., Aizawa, T., Igarashi, M. \& Yamazaki, J. (2007). Characteristics of congestive heart failure accompanied by atrial fibrillation with special reference to tachycardia-induced cardiomyopathy. Circulation eburnal, Vol. 71, No. 6, pp. 936-940. 
Fuster, V., Rydén, L.E., Cannom, D.S., Crijns, H.J., Curtis, A.B., Ellenbogen, K.A., Halperin, J.L., Kay, G.N., Le Huezey, J.Y., Lowe, J.E., Olsson, S.B., Prystowsky, E.N., Tamargo, J.L. \& Wann, L.S. (2011). 2011 ACCF/AHA/HRS focused updates incorporated into the ACC/AHA/ESC 2006 guidelines for the management of patients with atrial fibrillation: a report of the American College of Cardiology Foundation/ American Heart Association Task Force on Practice Guidelines. JAm Coll Cardiol, Vol. 57, No. 11, pp. e101-e198.

Kurian, T., Ambrosi, C., Hucker, W., Fedorov, V.V. \& Efimov, I.R. (2010). Anatomy and electrophysiology of the human AV node. Pacing Clinc Electrophysiol, Vol. 33, No. 6, pp. 754-762.

Leon, A.R., Greenberg, J.M., Kanuru, N., Baker, C.M., Mera, F.V., Smith, A.L., Langberg, J.J. \& DeLurgio, D.B. (2002). Cardiac resynchronization in patients with congestive heart failure and chronic atrial fibrillation: effect of upgrading to biventricular pacing after chronic right ventricular pacing. JAm Coll Cardiol, Vol. 39, No. 8, pp. 1258-1263.

Lewis, R.V., McMurray, J. \& McDevitt, D.G. (1989). Effects of atenolol, verapamil, and xamoterol on heart rate and exercise tolerance in digitalised patients with chronic atrial fibrillation. JCardiovasc Pharmacol, Vol. 13, No. 1, pp. 1-6.

Garrigue, S., Tchou, P.J. \& Mazgalev, T.N. (1999). Role of the differential bombardment of atrial inputs to the atrioventricular node as a factor influencing ventricular rate during high atrial rate. Cardiovasc Res, Vol. 44, No. 2, pp. 344-355.

Greener, I.D., Monfredi, O., Inada, S., Chandler, N.J., Tellez, J.O., Atkinson, A., Taube, M.A., Billeter, R., Anderson, R.H., Efimov, I.R., Molenaar, P., Sigg, D.C., Sharma, V., Boyett, M.R. \& Dobrzynski, H. (2011). Molecular architecture of the human specialised atrioventricular conduction axis. JMol Cell Cardiol, Vol. 50, No. 4, pp. 642-651.

Greenhut, S.E., Fraser, J., Steinhaus, B., Feld, G. \& Hughes, W. (1996). Optimized standby rate reduces the ventricular rate variability in pacemaker patients with atrial fibrillation. Pacing Clin Electrophysiol, Vol. 19, No. 11, pp. 1780-1785.

Groenveld, H.F., Crijns, H.J., Rienstra, M., van den Berg, M.P., van Veldhuisen, D.J., van Gelder, I.C. \& RACE investigators. (2009). Does intensity of rate control influence outcome in persistent atrial fibrillation? Am Heart J, Vol. 158, No. 5, pp. 785-791.

Grogan, M., Smith, H.C., Gersh, B.J. \& Wood, D.L. (1992). Left ventricular dysfunction due to atrial fibrillation in patients initially believed to have idiopathic dilated cardiomyopathy. Am JCardiol, Vol. 69, No. 19, pp. 1570-1573.

Hagens, V.E., Crijns, H.J., van Veldhuisen, D.J., van den Berg, M.P., Rienstra, M., Ranchor, A.V., Bosker, H.A., Kamp, O., Tijssen, J.G., Veeger, N.J., van Gelder, I.C. \& RACE study group (2005). Rate control versus rhythm control for patients with persistent atrial fibrillation with mild to moderate heart failure: results from the RAte Control versus Electrical cardioversion (RACE) study. Am Heart J, Vol. 149, No. 6, pp. 11061111.

Hayes, D.L., Boehmer, J.P., Day, J., Gilliam, F.R.3rd, Heidenreich, P.A., Seth, M., Jones, P.W. \& Saxon, L.A. (2011). Cardiac resynchronization therapy and the relationship of percent biventricular pacing to symptoms and survival. Heart Rhythm, in press. 
Hnatkova, K., Waktare, J.E., Murgatroyd, F. D., Guo, X., Camm, A.J. \& Malik M. (1998). Age and gender influences on rate and duration of paroxysmal atrial fibrillation. Pacing Clin. Electrophysiol, Vol. 21, No. 11, pp. 2455-2458.

Kay, G.N., Ellenbogen, K.A., Giudici, M., Redfield, M.M., Jenkins, L.S., Mianulli, M. \& Wilkoff, B. (1998). The Ablate and Pace Trial: a prospective study of catheter ablation of the AV conduction system and permanent pacemaker implantation for treatment of atrial fibrillation. APT Investigators. JInterv Card Electrophysiol, Vol. 2, No. 2, pp. 121-135.

Lundström, T. \& Rydén, L. (1990). Ventricular rate control and exercise performance in chronic atrial fibrillation: effects of diltiazem and verapamil. JAm Coll Cardiol, Vol. 16, No. 1, pp. 86-90.

Meijler, F.L. \& Janse, M.J. (1988). Morphology and electrophysiology of the mammalian atrioventricular node. Physiol Rev, Vol. 68, No. 2, pp. 608-647.

Nerheim, P., Birger-Botkin, S., Piracha, L. \& Olshansky, B. (2004). Heart failure and sudden death in patients with tachycardia-induced cardiomyopathy and recurrent tachycardia. Circulation, Vol. 110, No. 3, pp. 247-252.

Olshansky, B., Rosenfeld, L.E., Warner, A.L., Solomon, A.J., O'Neill, G., Sharma, A., Platia, E., Feld, G.K., Akiyama, T., Brodsky, M.A., Greene, H.L. \& AFFIRM Investigators. (2004). The Atrial Fibrillation Follow-up Investigation of Rhythm Management (AFFIRM) study: approaches to control rate in atrial fibrillation. JAm Coll Cardiol, Vol. 43, No. 7, pp. 1201-1208.

Page, R.L., Connolly, S.J., Crijns, H.J., van Eickels. M., Gaudin, C., Torp-Pedersen, C., Hohnloser, S.H. \& ATHENA Investigators. (2011). Rhythm- and rate-controlling effects of dronedarone in patients with atrial fibrillation (from the ATHENA trial). Am JCardiol, Vol. 107, No. 7, pp. 1019-1022.

Petri, H., Kafka, W., Rudolph, W. (1983). Discrepant effects of oral and intravenous verapamil on $\mathrm{A}-\mathrm{V}$ conduction in patients with ventricular preexcitation and atrial fibrillation. Herz, Vol. 8, No. 3, pp. 144-152.

Roka, A., Toth, E., Szilagyi, S. \& Merkely, B. (2008). Electrical atrial fibrillation induction affects the characteristics of induced arrhythmia. JElectrocardiol, Vol. 41, No. 2, pp. 131-137.

Roka, A. \& Merkely, B. (2008). Development and validation of a model of atrioventricular conduction in atrial fibrillation based on junctional intracardiac electrograms. Comp Cardiol, Vol. 35, No. 1, pp. 405-408.

Segal, J.B., McNamara, R.L., Miller, M.R., Kim, N., Goodman, S.N., Powe, N.R., Robinson, K., Yu, D. \& Bass, E.B. (2000). The evidence regarding the drugs used for ventricular rate control. JFam Pract, Vol. 49, No. 1, pp. 47-59.

Shinbane, J.S., Wood, M.A., Jensen, D.N., Ellenbogen, K.A., Fitzpatrick, A.P. \& Scheinman MM. (1997). Tachycardia-induced cardiomyopathy: a review of animal models and clinical studies. JAm Coll Cardiol, Vol. 29, No. 4, pp. 709-715.

Simpson, C.S., Yee, R., Lee, J.K., Braney, M., Klein, G.J., Krahn, A.D. \& Skanes, A.C. (2001). Safety and feasibility of a novel rate-smoothed ventricular pacing algorithm for atrial fibrillation. Am Heart J, Vol. 142, No. 2, pp. 294-300. 
Siu, C.W., Lau, C.P., Lee, W.L., Lam, K.F. \& Tse, H.F. (2009). Intravenous diltiazem is superior to intravenous amiodarone or digoxin for achieving ventricular rate control in patients with acute uncomplicated atrial fibrillation. Crit Care Med, Vol. 37, No. 7, pp. 2174-2179.

Stein, K.M., Walden, J., Lippman, N. \& Lerman, B.B. (1999). Ventricular response in atrial fibrillation: random or deterministic? Am JPhysiol, Vol. 277, No. 2, pp. H452-H458.

Stiell, I.G., Clement, C.M., Brison, R.J., Rowe, B.H., Borgundvaag, B., Langhan, T., Lang, E., Magee, K., Stenstrom, R., Perry, J.J., Birnie, D. \& Wells, G.A. (2011). Variation in management of recent-onset atrial fibrillation and flutter among academic hospital emergency departments. Ann Emerg Med, Vol. 57, No. 1, pp. 13-21.

Tse, H.F., Lam, Y.M., Lau, C.P., Cheung, B.M. \& Kumana, C.R. (2001). Comparison of digoxin versus low-dose amiodarone for ventricular rate control in patients with chronic atrial fibrillation. Clin Exp Pharmacol Physiol, Vol. 28, No. 5-6, pp. 446-450.

Tse, H.F., Newman, D., Ellenbogen, K.A., Buhr, T., Markowitz, T., Lau, C.P. \& Atrial Fibrillation SYMPTOMS investigators (2004). Effects of ventricular rate regularization pacing on quality of life and symptoms in patients with atrial fibrillation (Atrial fibrillation symptoms mediated by pacing to mean rates [AF SYMPTOMS study]). Am JCardiol, Vol. 94, No. 7, pp. 938-941.

Upshaw, C.B.Jr. (1997). Hemodynamic changes after cardioversion of chronic atrial fibrillation. Arch Intern Med, Vol. 157, No. 10, pp. 1070-1076.

Vago, H., Roka, A., Acsady, G. \& Merkely, B. (2004). Parasympathetic cardiac nerve stimulation with implanted coronary sinus lead. JCardiovasc Electrophysiol, Vol. 15, No. 5, pp. 588-590.

van den Berg, M.P., de Langen, C.D., Haaksma, J., Bel, K.J., Crijns, H.J., Dijk, W.A. \& Lie, K.I. (1995). Analysis of randomness of atrial and ventricular rhythm in atrial fibrillation. Eur Heart J, Vol. 16, No. 7, pp. 971-976.

van den Berg, M.P., Brouwer, J., Tieleman, R.G., Mulder, G \& Crijns H.J. (1997). Heart rate variability in patients with atrial fibrillation is related to vagal tone. Circulation, Vol. 96, No. 4, pp. 1209-1216.

van Gelder, I.C., Wyse, D.G., Chandler, M.L., Cooper, H.A., Olshansky, B., Hagens, V.E., Crijns, H.J. \& RACE and AFFIRM Investigators. (2006). Does intensity of ratecontrol influence outcome in atrial fibrillation? An analysis of pooled data from the RACE and AFFIRM studies. Europace, Vol. 8, No. 11, pp. 935-942.

van Gelder, I.C., Groenveld, H.F., Crijns, H.J., Tuininga, Y.S., Tijssen, J.G., Alings, A.M., Hillege, H.L., Bergsma-Kadijk, J.A., Cornel, J.H., Kamp, O., Tukkie, R., Bosker, H.A., van Veldhuisen, D.J., van den Berg, M.P. \& RACE II Investigators. (2010). Lenient versus strict rate control in patients with atrial fibrillation. New Eng JMed, Vol. 362, No. 15, pp. 1363-1373.

Weerasooriya, R., Davis, M., Powell, A., Szili-Torok, T., Shah, C., Whalley, D., Kanagaratnam, L., Heddle, W., Leitch, J., Perks, A., Ferguson, L. \& Bulsara, M. (2003). The Australian Intervention Randomized Control of Rate in Atrial Fibrillation Trial (AIRCRAFT). JAm Coll Cardiol, Vol. 41, No. 10, pp. 1697-1702. 
Wichmann, J., Ertl, G., Höhne, W., Schweisfurth, H., Wernze, H. \& Kochsiek, K. (1983). Alpha-receptor restriction of coronary blood flow during atrial fibrillation. Am $J$ Cardiol, Vol. 52, No. 7, pp. 887-892.

Williamson, B.D., Man, K.C., Daoud, E., Niebauer, M., Strickberger, S.A. \& Morady, F. (1995). Radiofrequency catheter modification of atrioventricular conduction to control the ventricular rate during atrial fibrillation. New Eng JMed, Vol. 331, No. 14, pp. 910-917.

Wittkampf, F.H., de Jongste, M.J., Lie, H.I. \& Meijler, F.L. (1988). Effect of right ventricular pacing on ventricular rhythm during atrial fibrillation. JAm Coll Cardiol, Vol. 11, No. 3, pp. 539-545.

Wood, M.A., Brown-Mahoney, C., Kay, G.N. \& Ellenbogen, K.A. (2000). Clinical outcomes after ablation and pacing therapy for atrial fibrillation : a meta-analysis. Circulation, Vol. 101, No. 10, pp. 1138-1144. 


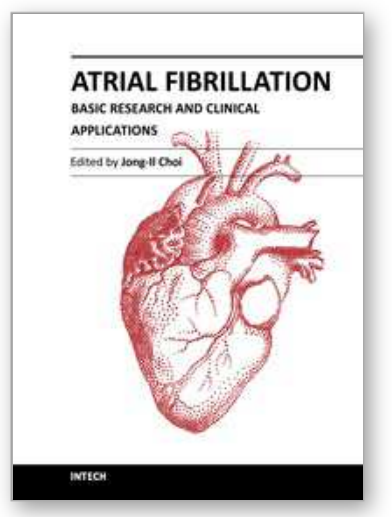

\author{
Atrial Fibrillation - Basic Research and Clinical Applications \\ Edited by Prof. Jong-II Choi
}

ISBN 978-953-307-399-6

Hard cover, 414 pages

Publisher InTech

Published online 11, January, 2012

Published in print edition January, 2012

Atrial Fibrillation-Basic Research and Clinical Applications is designed to provide a comprehensive review and to introduce outstanding and novel researches. This book contains 22 polished chapters and consists of five sections: 1. Basic mechanisms of initiation and maintenance of atrial fibrillation and its pathophysiology, 2 . Mapping of atrial fibrillation and novel methods of signal detection. 3. Clinical prognostic predictors of atrial fibrillation and remodeling, 4. Systemic reviews of catheter-based/surgical treatment and novel targets for treatment of atrial fibrillation and 5. Atrial fibrillation in specific conditions and its complications. Each chapter updates the knowledge of atrial fibrillation, providing state-of-the art for not only scientists and clinicians who are interested in electrophysiology, but also general cardiologists.

\title{
How to reference
}

In order to correctly reference this scholarly work, feel free to copy and paste the following:

Attila Roka (2012). Atrioventricular Conduction in Atrial Fibrillation: Pathophysiology and Clinical Implications, Atrial Fibrillation - Basic Research and Clinical Applications, Prof. Jong-II Choi (Ed.), ISBN: 978-953-307-399-6, InTech, Available from: http://www.intechopen.com/books/atrial-fibrillation-basic-research-and-clinicalapplications/atrioventricular-conduction-in-atrial-fibrillation-pathophysiology-and-clinical-implications

\section{INTECH}

open science | open minds

\section{InTech Europe}

University Campus STeP Ri

Slavka Krautzeka 83/A

51000 Rijeka, Croatia

Phone: +385 (51) 770447

Fax: +385 (51) 686166

www.intechopen.com

\section{InTech China}

Unit 405, Office Block, Hotel Equatorial Shanghai

No.65, Yan An Road (West), Shanghai, 200040, China

中国上海市延安西路65号上海国际贵都大饭店办公楼405单元

Phone: +86-21-62489820

Fax: +86-21-62489821 
(C) 2012 The Author(s). Licensee IntechOpen. This is an open access article distributed under the terms of the Creative Commons Attribution 3.0 License, which permits unrestricted use, distribution, and reproduction in any medium, provided the original work is properly cited. 